\title{
Recycling Mechanisms - a Survey of Current Policy Options
}

\author{
Lal Jayawardena
}

It is now widely accepted that the recycling of surpluses by the private banking system in the 1970s contributed to maintaining global activity through sustaining developing country purchasing power. What occurred in fact was a process of "massive transfer' under the aegis of the private sector which had the effect of partially offsetting the recessionary impact of the oil price increase. With the onset of the second oil crisis the capacity of the banking system to continue with this process was widely questioned; indeed the European Commission placed on record its view two years ago that, as contrasted with the period after the first oil crisis, "the private banking sector is no longer enough' [EEC 1981].

It is worth dwelling briefly on the reasons for this:

- there is a concern that, with the total developing country debt rising to $\$ 425 \mathrm{bn}$ at the end of 1981 , and with servicing costs exceeding on average over 20 per cent of their export earnings, this will inhibit access to banking credit;

- secondly, there is a concern that country limits are being approached by the banking system for an increasing number of developing countries. Since a very large proportion of bank lending is concentrated in a few countries - some 12 in number - the deflationary implications are serious;

- thirdly, banks are becoming concerned about the adequacy of their capital in relation to the total size of their deposits - a point also specifically made in the Commonwealth Report [Arndt et al 1980];

- finally, there is the problem of how far the process of the banks borrowing short and lending long can be sustained if the confidence of short-term depositors such as OPEC is eroded by even a single banking crisis.

\section{Proposals for Recyling in Favour of the Third World}

If this is accepted, the question that arises is what other surrogates to the private banks' recycling role are now available. This article seeks to explore the alternatives that are open to the international community, and in particular the EEC. Among the various possible arrangements, one concerns a specifically EEC institution, viz the European Investment Bank (EIB), which has already, so to speak, crossed the gearing ratio bridge. The EIB is capable of lending up to 250 per cent of its capital, which has recently been increased from 7 to 14 bn EUAs. Its gearing ratio therefore will permit the EIB to lend up to 250 per cent of this amount or $36 \mathrm{bn}$ EUA. Deducting loans currently outstanding of nearly 14 bn EUA, leaves the EIB with a lending capability of 22 bn EUA. Its current bond issues have been in the region of $3 \mathrm{bn}$ EUA annually. It should be possible therefore to use this increased capital base to raise say an additional $\$ 1$ bn annually and relend the amount on substantially concessional terms if current amounts disbursed by the European Commission to non-ACP countries as grant aid, around $200 \mathrm{mn}$ EUA, are all diverted to interest subsidy purposes. In other words, using the EIB's enhanced guarantee capability could convert a modest amount of grant aid into a substantial multiple of it for purposes of moderately concessional lending. While the magnitudes involved do not of course mean 'massive transfers', the approach does expand the transfer potential of available budgetary aid amounts. This mechanism has been put to the Commission in the context of lending for New and Renewable Energy purposes and is under serious consideration. More ambitious proposals go beyond the notion of varying existing guarantee capability to establish an explicit large-scale fund for the channelling of 'massive transfers' for desirable developmental purposes, in particular to fill the prevailing gaps in the existing financial structure. The design currently available for discussion is of course the Brandt Commission's World Development Fund, building up to an annual lending programme of $\$ 20 \mathrm{bn}$ at the end of a sevenyear period.

Proposals which seek to link official arrangements for protecting the real value of OPEC assets with the long-term financing of developing country deficits through providing resources for a World Development Fund surfaced more or less simultaneously in mid1980 in the Commonwealth Report [Arndt et al 1980 
ch 3 and Appendix 1], in what has come to be known as the Gutowski/Roth Plan [Roth 1980], and in a variant of this latter proposal put forward by the European Parliament involving action initially at the level of the European Community and the Gulf States [EEC 1980]. ${ }^{1}$

The Commonwealth Expert Group model implies relatively modest protection for OPEC assets protection against exchange risks only - but also places fewer demands on international cooperation in general and on OPEC in particular [Arndt et al 1980; Jayawardena 1980]. By the same token it has the disadvantage of not going far enough by failing fully to insure against the risk of periodic and unilateral price action by OPEC countries as they seek to offset the erosion in the real value of their assets through inflation. The Commonwealth proposal proceeds through a series of steps in financial inter-mediation which we summarise as follows:

We strongly recommend that negotiations between interested parties should commence without delay to take the following steps: first, the provision of facilities for reserve diversification by the oilexporting countries, whether through off-market transactions which would, in effect, create a tier of secondary reserve assets for the participating central banks or through the proposed IMF Substitution Account; second, the on-lending of such funds via the IMF to developing countries on suitable terms for financing their deficits; and third, consideration of possible ways of making this on-lending process the starting point for longterm programme financing. A feasible mechanism might be the negotiation between governments of appropriate guarantee arrangements. This could later be given permanent form by converting the guarantees into the callable capital (in the sense of a system of limited 'joint and several guarantees') of a lending institution.

[Jayawardena 1980:84]

The Gutowski/Roth Plan seeks to offer OPEC the required greater degree of protection for its assets by including additional measures designed to make the value of oil underground fully equivalent to that of oil converted into financial assets. This involves mutual agreement on a steady annual rate of increase in the real price of oil and on an equivalent real rate of return on the financial assets, to be denominated in SDRs, into which oil will have been converted. OPEC is therefore fully protected against both inflation and exchange risks. This greater benefit to OPEC is sought to be traded against long-term assurances of supply

${ }^{1}$ Wolfgang Roth is a Federal German MP and Chairman of the Committee on Development of the Social Democratic Party, and Professor Armin Gutowski is President of HWWA - Institut für Wirtschaftsforschung, Hamburg. The Gutowski/Roth Plan is also described in Wirtschaftsdienst no 2, December 1980, Hamburg. and, of course, orderly price increases, and therefore makes greater demands on OPEC than does the Commonwealth proposal. The mechanics of the Gutowski/Roth Plan imply offering OPEC annually securities of up to $\$ 40 \mathrm{bn}$. These are in the nature of 10-year bonds convertible into cash after a minimum period of notice assumed in the plan to be three months. The dollars with which OPEC will pay for these securities are invested by the institution administering the plan in the international capital markets. To the extent to which the return on the dollar portfolio falls short of the inflation indexed return guaranteed to OPEC, there will be a subsidy burden on OECD budgets. An annual fraction of the $\$ 40 \mathrm{bn}$ (upwards of $\$ 10 \mathrm{bn}$ ) is earmarked for providing resources to a World Development Fund for subsidised lending to developing countries, and is not available for investment in capital markets. This latter subsidy benefitting developing countries would be divided between OPEC and the OECD. The European Parliament External Relations Committee's proposal seeks in effect to reduce the Gutowski/Roth Plan to a limited, sectional initiative on the part of the European Community and the surplus Gulf states. All three proposals provide, as mentioned, as an integral part of their formulation, for longer term lending to developing countries by finding substantial resources for financing a World Development Fund.

The question that arises is whether in the current state of the world economy any proposal along these lines can have a reasonable chance of being negotiated. Let me at the outset identify what seem to be areas of inherent political implausibility in this category of proposals. Firstly, any attempt to work out a longterm agreement on the price of oil has the implausibility that it may be thought of as derogating from the national sovereignty of OPEC countries, and, more particularly, of derogating from the freedom OPEC would wish to have to link questions of the oil price with a wider package involving both international political and economic questions. For this reason difficulties may arise in implementing the Gutowski/Roth Plan as formulated, in particular the attempt to link the real rate of return of OPEC assets and the price of oil in the form of an explicit agreement.

The second area of political implausibility relates to the notion of anything savouring of a separate political deal involving an assurance of oil prices and supplies between a part, however significant, of OPEC and a part of the OECD, namely the European Community. Since pricing decisions would require the involvement of all of OPEC, and since OPEC is committed to deploying any leverage in the area of oil on behalf of the entire Group of 77, any deal outside the UN Global Round has an inherent political 
weakness. It is difficult therefore to see clearly the lines of a politically negotiated solution to both sets of problems outside the proposed United Nations Global Round where the opportunity would arise to deploy Third World leverage in the area of energy temporary periods of softness in the oil market such as today's notwithstanding - to negotiate a complex package involving not only financing issues but those relating to trade and transfer of technology as well, to pick only two other areas.

\section{A Role for the EEC}

What I suggest could provide a basis for forward movement would be an independent initiative that would fashion, at the level of the European Community for example, a financial instrument which will provide an attractive medium for the investment of developing country surpluses, and which goes beyond the self-imposed limitation of the Commonwealth Report by moving in the direction of a link with OECD inflation rates. An SDR denominated bond would have such an effect and would be an appropriate basis for determining a positive real interest rate. Such a proposal, in the absence of an accompanying agreement on oil prices and supplies, would not of course make OPEC completely indifferent as between oil above ground and oil below ground. But it could diminish appreciably the pressure that will arise when OECD recovery occurs to restrict supplies and charge the maximum market rate to make up for past erosions in the real value of assets.

How can an initiative of this kind serve to safeguard the future macro-economic well-being of the world economy, in the absence of the parallel agreement with OPEC that would alone guarantee a predictable price of oil over the long term, but which I have ruled out as possibly not negotiable in advance? The solution might well consist in timing the introduction of a sufficient volume of an inflation-indexed asset for a moment of appropriate 'softness' in the oil market. Certainly one way of ensuring the desired predictability is to couple the introduction of the inflation-indexed asset I have mentioned with an indication of the minimum amounts likely to be offered annually for, say, a five-year period, and with an announcement that the annual offer will lapse if at any time the real price of oil were to increase by more than a specific annual percentage above that of a base line period. A unilateral Community offer of this kind can only be made during a period when the oil market is soft enough for the base line price to be set at a level just adequate to assist the 'energy transition' from nonrenewable to other forms of energy. If properly timed, it should go far towards ensuring predictability in the price of oil. The economic effect of such an initiative can be expected, in fact, to be equivalent to that of the oil price formula in the OPEC long-term strategy, depending on the level at which the base line price is set and the factors taken into account in determining the minimum permissible annual increment in the real price of oil.

If Europe were to be generous in a spirit of enlightened self-interest, it might wish further to demarcate some minimum portion of this offer in securities denominated in SDRs only - therefore carrying a guarantee against exchange risk alone without any coverage for inflation risk - on the condition that OPEC as a grouping would implement that part of its long-term strategy aimed at converting oil price increases beyond a base line price into loans of varying concessionality for oil-importing developing countries. This, it will be recalled, sought to provide finance on varying terms to countries at different levels of development. It sought to give interest-free long-term loans to countries with less than $\$ 300$ per capita income importing less than 10,000 barrels a day of oil; concessional long-term loans with a 25 to 50 per cent grant element to countries with per capita income of between $\$ 300$ and $\$ 1,000$ and oil imports of between 10,000 and 100,000 barrels a day; and to countries with a per capita income of more than $\$ 1,000$ and oil imports of more than 100,000 barrels a day it offered medium-term commercial loans. The minimum volume of exchange risk proof securities offered by the EEC could always be equated to the concessional financing burden so assumed by OPEC. The effect of such an arrangement would be to maintain Third World purchasing power and creditworthiness, which would benefit the Community, while offering OPEC a significant measure of protection.

If these two classes of security were to be offered through an institution of the kind contemplated in the Gutowski/Roth Plan, then the problem would be to assure its solvency. This problem would arise if the institution's liabilities in respect of interest payment obligations were to exceed the return on the portfolio of assets acquired by investing the dollars paid by OPEC countries for their protected securities. One problem which has complicated the further discussion of the Gutowski/Roth Plan has been the prospect that any such excess would become a subsidy burden falling upon OECD governments. If, however, the institution were authorised to invest its dollars in equities which hedge against inflation as well as other instruments, the institution's viability could be ensured at the cost of some sacrifice in the ease with which OPEC could convert their 'protected' securities into cash. A trade-off could surely be found in a more detailed formulation of this proposal which would ensure the institution's financial viability, and a balance between protection of value and liquidity for the securities issued to OPEC so as to leave developed 
country governments with a subsidy burden imputable solely to the cost of lending under the World Development Fund component of the proposal. Under appropriate circumstances SDR creation could finance any such subsidy amount without burdening government budgets.

A balanced package involving the adaptation of the Gutowski/Roth Plan to a 'soft' oil market situation is outlined below in terms of the respective obligations of the Community, of the institution administering the plan (which might be the EIB) and of OPEC.

The Community's obligations The Community would meet any interest subsidy cost on that portion of the institution's assets devoted to lending to developing countries. It would make a minimum issue of exchange-risk protected securities in an amount equivalent to the estimated annual volume of concessional financing granted by OPEC to developing countries to meet price increases above the base line oil price. It would make a supplementary issue of both exchange-risk and inflation-risk protected securities which would lapse if the real price of oil increases annually by a fixed percentage above the base line price. It could keep institution building to a minimum by issuing the protected securities through a window of the EIB.

The institution's obligations The asset portfolio of the institution will be distributed as between equities and other assets in such a manner as to ensure an acceptable combination of protection of value and liquidity of the counterpart securities for OPEC so that the fund becomes viable except for the subsidy component on World Development Fund lending; the limits to OPEC illiquidity ought to be capable of being specified in advance.

OPEC's obligations OPEC would implement for developing countries the proposals contained in its long-term strategy for concessional financing of oil imports. It would 'accept' the restrictions needed on encashing its protected securities if the financial viability of the institution is to be preserved without a subsidy on EEC budgets other than the amount required to subsidise World Development Fund lending; no prior agreement needs to be arrived at for the reason that OPEC's, or for that matter other surplus countries' 'absorption' of the securities will depend on the balance provided between protection of real value and liquidity, and there will be substantial scope for varying both this balance and the amount offered so as to equate supply and demand for the securities.

This way of approaching the Gutowski/Roth Plan would enable the Community to take a bold initiative in the context of a 'soft' oil market, without entering into complex negotiations exposing it to an unpredictable financial risk, while simultaneously conferring a benefit on OPEC, the developing countries and, above all, on itself.

\section{References}

Arndt, H. W. et al, 1980, The World Economic Crisis: a Commonwealth Perspective: a report of a group of experts, Commonwealth Secretariat, London, June

EEC, 1980, Draft Report on Trade Relations between the EEC and the Gulf States, European Parliament Committee on External Economic Relations, Luxembourg

EEC, 1981, European Commission Communication to the European Council in Maastricht on the North-South Dialogue, European Report no 761, Brussels, 21 March

Jayawardena, Lal, 1980, 'The massive transfer of resources to developing countries', paper contributed to Commonwealth Group of Experts, March, and to the International Banking Conference, Dubrovnik, May

Roth, Wolfgang and Armin Gutowski, 1980, Draft of a Contractual Agreement between OPEC Countries, Industrial Countries and Developing Countries, Hamburg 